\title{
A velha roupa colorida: Brasil e África na Geggrafia Escolar
}

\section{The old colorful clothes: Brazil and Africa in School Geggraphy}

Aos irmãos-de-santo

Fabia Ribeiro e Pedro Leyva

da casa Îlé Òdé Axé Obà Omin de pai Everaldo Cardoso.

Rosemberg Lopes Ferracini*

\section{Resumo:}

O presente texto tem como objetivo discutir as proximidades teóricas curriculares e as disparidades praticadas - brasilianas- com relação ao continente africano. Passados dez anos de conquista alguns temas foram sedimentados, outros rompidos, poucos esquecidos e muitos permanecem nas práticas escolares. Apresentaremos como algumas reaproximações do Brasil com o continente africano que passam pelo debate no ensino do discurso político como as 'políticas territoriais', de economia via 'transações econômicas', e pela cultura com as trocas humanas 'África-Brasil'. O ponto significativo é analisar que o passado colonial não acabou, apenar trocou de roupagem e necessita ser analisado com cuidado nas práticas de ensino e aprendizagem.

\section{Abstract:}

The present text has as objective to discuss the proximal curricular theories and the disparities practiced -Brazilian- with respect to the African continent. After ten years of conquest some themes were settled, others broken, few forgotten and many remain in school practices. We will present how some rapprochements of Brazil with the African continent that pass through the discussion in the teaching of the political discourse as the 'territorial policies', of economy via 'economic transactions', and by the culture with the human exchanges 'Africa-Brazil'. The significant point is to analyze that the colonial past has not ended, but rather has changed clothes and needs to be carefully analyzed in the teaching and learning practices.

* Dr. em Geografia Humana pela USP. Professor na Universidade Federal do Tocantins, UFT/Porto Nacional, membro do Laboratório de Práticas e Metodologias de Ensino de Geografia (LEGEO) UFT.
Palavras-chave: Brasil, África, Política, Cultura

Keywords: Brazil, Africa, Politic, Culture 


\section{INTRODUÇÃO}

$\mathrm{O}$ texto que se segue foi apresentado e debatido no primeiro semestre de 2016 no Seminário Permanente de Estudos Africanos na UNILAB, Universidade da Integração Internacional da Lusofonia Afro-Brasileira, Campus dos Malês, tendo como tema "Aproximações Brasil-África". Aqui ousamos em problematizar e lançar para os colegas professores algumas propostas para futuras aulas e pesquisas a respeito do continente africano e suas reaproximações com o Brasil. Acreditamos ser importante pensar em novas reflexões de ensino sobre África. Ao assumirmos tal postura, demonstramos que não pretendemos enveredar por um individualismo metodológico. Contudo buscamos articular o conjunto de autores que discutem com uma matriz epistemológica próxima de combinações, teorias, compatibilidades, precisões e que tenham um posicionamento acerca do debate do ensino de África na Geografia Escolar.

Para tal lançamos três perguntas dilemáticas que devem ser pensadas tendo como exemplo o velho e bondoso imperialismo da metade do século XIX. O que são os novos laços de união do Brasil com os países do continente africano? Seriam eles práticas que podem ser denominadas de uma colonização disfarçadas de verde-amarelo? Tal aproximação nos dias de hoje está relacionada com a ocupação de novos órgãos governamentais em terras estrangeiras?

Para buscar responder tais indagações buscaremos aportes pontuais. Um exemplo desse movimento é que nas últimas décadas diferentes linhas de pesquisas, disciplinas de graduação, pós-graduação, a publicação de livros e artigos a respeito da África vêm surgindo no Brasil. Baseado em experiências de sala de aula, nossa proposta tem sido de aprofundar e melhorar a formação de professores nessa temática, no caso da Geografia são poucos os interesses. Mesmo com a ausência dos colegas da ciência da terra surge $o$ apoio das agências de fomento em trazer uma África desconhecida para os brasileiros que urge em ser desmistificada. Pesquisas com viés africanista, desde a educação, política, sociologia, história, literatura, artes, ciência e conhecimentos cartográficos estão sendo publicadas e divulgada em revistas especializadas, periódicos e livros de grande acesso à população brasileira. Exemplo desse fato é tradução e publicação das obras da Unesco em português em 2010. Uma coleção de obras compostas de oito exemplares onde se pode encontrar um rico conjunto de informações que contribuem para uma nova forma de olharmos para esse continente. Em pesquisa nos volumes é possível encontrar dados, tabelas, mapas e demais fontes importantes para futuras investigações escolares e acadêmicas a respeito do continente africano.

A Lei $n^{\circ} 10.639 / 03$, como o conjunto das obras traduzidos, publicados e disponibilizados online pela Unesco, propõe que os estabelecimentos de educação básica, infantil, fundamental, de ensino médio, e de jovens e adultos precisam estar munidos de livros e materiais didáticos que tratem desse tema em específico. Com a leitura e análise do material podemos observar que são diversos os autores que compõem cada volume, constando africanistas dos diversos continentes, em sua maioria africanos. Cada pesquisador trata de aspectos específicos, contribuindo para um novo olhar e pesquisas para o continente africano. O conjunto das informações a respeito de mapas, figuras e tabelas ajuda na construção de um novo olhar para o continente africano. Seguramente tal conjunto das obras publicadas muda o foco do debate, diferente daquele da colonização racista europeia presente nas traduções de língua portuguesa.

Como explanado por Ferracini (2012, p.18), "o campo de pesquisa da África no livro didático no ensino da Geografia é vasto, caro e ainda pouco explorado pelo viés escolar". Da mesma forma existem outros recortes e interpretações teóricas que podem vir a ser desenvolvidos entre levantamentos de trabalhos a respeito do tema, explicações e réplicas para um maior desenvolvimento desse desafio.

Podemos afirmar que anteriormente à Lei $\mathrm{n}^{\circ}$ 10.639/03, o tema da África até recebia uma atenção direcionada no ensino de Geografia brasileira, em particular com interesses eurocêntricos, sobre os quais muito se discutiu em debates acadêmicos e pesquisas, não só sobre a África especificamente, mas também sobre as africanidades e as relações étnico-raciais no território brasileiro.

Em particular nos currículos escolares, estes fazem parte de cada realidade específica, isso porque em muitos deles estão inseridos em algumas circunstâncias políticas que envolveram a África, aspectos históricos da política colonial e o processo de sua independência, descolonização e a afirmação de alguns países como Estados. A África ainda possui um vasto campo de pesquisa que passa pelo período anticolonial, o colonial, do apartheid, o pós-colonial, até nossos dias. Os temas que passam pela rica hidrografia, a diversidade populacional, a variedade paisagística da fauna e flora, as riquezas minerais, um vasto campo religioso, 
suas festas e tradições que se misturam e confundem com as línguas maternas e o seu sistema de ensino. Conteúdos de aprendizagem que passam pelos blocos econômicos, a sua divisão regional e integração territorial. Possibilitando uma gama de direcionamentos com os quais os currículos escolares podem se trabalhar e desenvolver, propondo recortes e diretrizes criativas e distintas para sala de aula.

\section{2. ÁFRICA E BRASIL NA FORMAÇÃO DE PROFESSORES}

Passaram-se dez anos da publicação da Lei e, alguns temas foram sedimentados, outros rompidos, alguns esquecidos das discussões curriculares. No entanto, há muitas permanências educacionais que merecem ser discutidas. Partindo do último ponto que é significativo para nós nesse texto, professores de Geografia, alguns dos nossos pares podem levantar argumentos de que estamos tendo má índole ao abordar esse tema.

Para nós o que importa é abrir o caminho para discussão de uma aprendizagem significativa, de explicar e compreender o mundo, as atuais integrações entre o Brasil e o continente africano. Nosso desafio é aproximar a teoria da prática. Como de situar o Brasil e os países africanos envolvidos nesse contexto social, como de construir instrumentos para tornar essa relação mais justa, que é o papel de debater as proximidades territoriais. Acreditamos que a Geografia, ao observar, analisar e compreender esse novo conjunto de relação contribui indo além de somente ter acesso a essas informações. Ela pensa as novas parcerias no contexto escolar e na formação do conjunto de pessoas envolvidas, tornando significativo tais conteúdos.

Por exemplo, internamente, na última década ocorreram mudanças internas e externas ao território brasileiro e ao continente africano que tiveram como objetivos ampliar as relações entre o Brasil e a África. A primeira delas se deu no campo da educação, quando em 10 de janeiro de 2003 o governo federal sancionou a Lei $n^{\circ}$ 10.639/03-MEC, que altera a LDB (Lei de Diretrizes e Bases), e estabelecendo as Diretrizes Curriculares para a implementação da obrigatoriedade do ensino da História da África e dos africanos no currículo escolar do ensino fundamental e médio. Posteriormente, em 21 de março do mesmo ano, criou-se a Secretaria Especial de Políticas de Promoção de Igualdade Racial (SEPPIR). A proposta do MEC/SEPPIR vem para contribuir para demais ações no campo do ensino, seja pelos materiais escolares, dos paradidáticos ou das mídias tecnológicas que possibilitem mudar o olhar não só da África no Brasil, como de repensarmos o lugar da África no mundo.

Entendemos que esses conjuntos de ações educativas vieram para fortalecer os patrimônios culturais na relação secular existente entre a África e o Brasil. Proximidade até então densamente trabalhada por nós na Geografia dos currículos escolares, nos cursos de formação de professores e nas salas de aulas. Fato é que o Brasil vem se fazendo cada vez mais presente no continente africano de diversas maneiras e realidade que precisa ser tratada com cuidado.

Retornando no tempo, no caso da África, a história não nega a corrida colonial europeia, quando os europeus buscavam, além dos levantamentos técnicos, aprofundar as relações econômicas e políticas com suas colônias. Foi quando já em meados do século XV a Europa já havia entrado em cena com a roedura da África com a utilização do braço africano para escravidão. Posteriormente no século XIX a concentração industrial que, em conjunto com o investimento do capital bancário, estabeleceram-se e financiaram-se as Sociedades Geográficas para a aquisição das novas terras no continente africano. Tais fatos podem ser interpretados com a ajuda da obra $\mathrm{O}$ imperialismo, fase superior do capitalismo, de Lênin (1917), e de África sob dominação colonial, 18801935 organizado pelo ganês Albert Adu Boahen (2010). Ambas tratam o fato geográfico da partilha da África e a exploração do mundo colonial imperial que passa pela construção da nação nos estados europeus tendo como suporte econômico o continente africano. $\mathrm{E}$ ao retomarmos essa discussão em sala de aula lembramos das Sociedades Geográficas, compostas pelos "homens do saber", tinham como ideal contribuir por meio do colonialismo para anexação de novas terras. Ao recordarmos um pouco a história escolar da nossa disciplina, voltamos a nossa indagação: o que seria bem os novos laços de união do Brasil com os países do continente africano?

\section{POR UMA OUTRA GEOPOLÍTICA ESCOLAR}

As (re)aproximações atuais entre o Brasil e o continente africano podem ser tratadas na disciplina escolar da Geografia pelo viés da política com as 'políticas territoriais', da economia via 'transações econômicas', e pela cultura com as trocas humanas 'África'-Brasil'. Essas três interpretações geográficas podem nos conduzir à necessidade de reformu- 
lar a pensar o processo de ensino e aprendizagem a respeito dessas novas relações Brasil-África.

A nosso ver, o governo brasileiro ao seguir sua proposta educacional do MEC/SEPPIR partiu para demais ações governamentais geopolíticas que ampliaram seu leque de ação. Foram elas as estratégias geoeconômicas, que ocorreram nesses últimos dez anos, por exemplo o "Projeto de cooperação Sul-Sul”, que vem buscando formar uma integração regional entre o Brasil e países africanos. Em discurso presidencial o governo brasileiro afirmou que sua proposta era criar uma "nova geografia política e econômica mundial", com objetivo de reatar a aliança política e econômica, reforçando as antigas partes históricas e culturais com as duas margens continentais do Atlântico. Uma identidade histórica e geográfica que não pode ficar ausente das conversas em sala de aula e que fortalece o ensino e aprendizagem a respeito do Brasil e do continente africano.

Ao recordarmos os fatos anteriores podemos falar de uma nova Geografia política e econômica no mundo. Lembramos do imperialismo conceituado por Lênin (1976), quando disse que essa prática estava ligada à expansão industrial capitalista de um grupo de países europeus. Essa leitura histórica pode nos ajudar a entender melhor a posição por parte do governo brasileiro, refutamos, seriam elas práticas que podem ser denominadas de uma colonização de verde-amarelo disfarçada? A nova corrida colonial, agora por parte do Brasil, coloca em jogo a busca de uma cadeira no Conselho de Segurança da Organização das Nações Unidas - ONU - . Para isso, percebe-se que o governo brasileiro está utilizando diferentes estratégias para alcançar sua meta, entre elas, a integração econômica e política com aqueles países localizados no Sul.

Fato é que nos últimos 10 anos as distâncias entre Brasil e África diminuíram em diferentes aspectos, como por exemplo, a abertura de novas representações diplomáticas, sendo o Brasil o país latino-americano com o maior número de embaixadas na África. Até o ano de 2002, o Brasil tinha 16 delas na África, nas cidades de Pretória, Luanda, Argel, Praia, Abidjan, Libreville, Acra, Bissau, Trípoli, Rabat, Maputo, Lagos, Nairóbi, Dacar, Túnis e Harare. Foram 33 viagens presidenciais ao continente, com a criação de 19 novas embaixadas. Hoje, no total, são 38 representações brasileiras na África, ficando atrás apenas da China, Estados Unidos, Rússia e França havendo acordos de cooperação técnica em 40 países do continente. A implantação de novas embaixadas no continente africano pode vir a ser analisada articuladamente buscando aprofundar as possibilidades de laços políticos, empresariais e educacionais. Será que a colonização dos dias de hoje está relacionada com a ocupação de novos órgãos governamentais em terras estrangeiras? Seriam as diplomacias brasileiras o exemplo do velho e bom colonialismo da metade do século XIX?

Em leitura do mapa abaixo, podemos dizer que o projeto Sul-Sul do governo brasileiro é parte de uma estratégia, uma política de inserção internacional direcionada para uma cooperação que passa pelo controle político, desenvolvimento econômico e difusão cultural. Os três trajetos sustentam o poder, legitimando o Brasil perante os países que aceitam a sua presença. Para essa articulação, diversas foram as ações implementadas na África e no Brasil seja de caráter econômico, técnico, cultural, científico e tecnológico com os países africanos, bem como nas trocas comerciais, e demais acordos. Segundo o IPEA (2016, p. 105) em 2003 foi realizado o "Fórum Brasil-África: Política, Cooperação e Comércio", com o objetivo criar um espaço para a discussão de temas relevantes para a aproximação das relações do Brasil com o continente africano, abarcando três campos: política e questões sociais; economia e comércio; e educação e cultura. Por exemplo, a criação da Cúpula América do Sul-África (ASA); a instalação de um escritório da Empresa Brasileira de Pesquisa Agropecuária (EMBRAPA) em Gana, sendo 18 projetos na África Ocidental, 18 na África Oriental e 03 na África Central ${ }^{1}$; na área da saúde foram firmados 53 atos bilaterais de cooperação com 22 países; a implementação do projeto "Fortalecimento das Ações de combate ao HIV/AIDS" que foi firmado com Quênia, São Tomé e Príncipe, Botsuana e Zâmbia. Um elemento de grande importância foi construção do Escritório Regional para África da Fundação Oswaldo Cruz (FIOCRUZ) em Maputo, com a presença da fábrica de antirretrovirais em Moçambique e de demais Centros de Formação Profissional nos países de língua portuguesa; de uma fazenda-modelo para a produção de algodão no Mali. Dentre os exemplos da presença brasileira no continente africano podemos interpretar e problematiza o mapa da figura 1 abaixo.

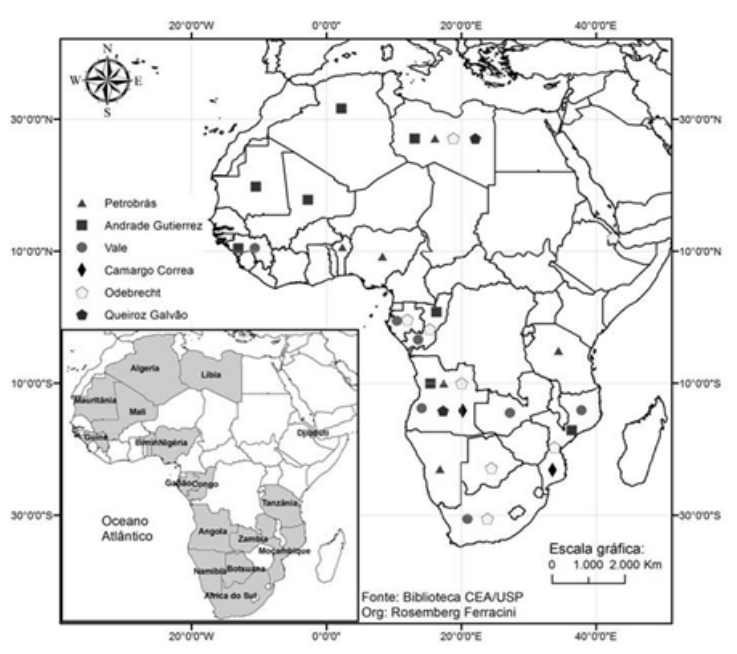

Figura 1 - Mapa do Brasil na África 
Em leitura do mapa anterior afirmamos que o professor de Geografia ao tratar o tema da África na sala de aula, não pode cair na armadilha pedagógica de induzir os alunos a pensarem que o Brasil está somente cooperando com o continente africano. Professores e alunos devem conversar a respeito das estratégicas que o governo brasileiro está utilizando para ir além do discurso educacional, culturalista e da dívida histórica com a escravidão. E sim problematizar a respeito da presença brasileira em terras africanas, que faz parte de um conjunto de sequências políticas que precisam ser abordadas com ressalvas.

Uma importante concretização no campo da educação formal foi a Universidade da Integração Internacional da Lusofonia Afro-Brasileira (UNILAB), sendo esta com metade das vagas para alunos africanos, com sua sede em Redenção no Ceará, nessa destacamos o campus de Malês na Bahia locada na cidade de São Francisco do Conde com um grande número de pesquisadores africanos e africanistas das ciências humanas. Pela Unilab houve a abertura do leitorado de língua e literatura brasileira no Camarões (que facilitou para que o mesmo se realizasse no Mali e Zâmbia). Seguramente as instalações brasileiras foram de interesse de ambas as partes envolvidas. Entretanto, na escola os alunos não podem receber estas informações passivamente, esse conhecimento precisa ser debatido e questionado.

Lemos anteriormente um conjunto de acordos que não podem ser tratados isoladamente, mas sim pela ampliação da escala do comércio entre o Brasil e os países africanos demonstrando um aprofundamento político e econômico. Temos o desenvolvimento nacional brasileiro buscando um novo lugar no sistema internacional. Uma estratégica que envolveu fatores de ordem econômica, via investimento brasileiro perante o mundo. $\mathrm{O}$ conhecimento geográfico continua sendo um importante instrumento para o avanço do capitalismo internacional. Não por acaso o governo brasileiro mensura, quantifica o território africano pois com estas informações terá sua missão acumulativa de capital.

Entre outras iniciativas políticas houve a participação do Brasil em diversas atividades que envolvesse o continente africano como a presença do ministro da Cultura em 2004 na I Conferência de Intelectuais da África e da Diáspora (CIAD), que teve como foco discutir os problemas contemporâneos e a relação África-Brasil. Como resultado ficou o compromisso do governo brasileiro de criar o "Centro Internacional da África e da Diáspora", e promover as trocas culturais afro-latino, através de iniciativas como o "Observatório Afro-Latino" e o I e II "Encontro Iberoamericano de Ministros da Cultura para a Agenda Afrodescendente nas Américas".

Essas discussões acadêmicas deram origem à "Declaração de Cartagena" - agenda afro-descendente nas Amé- ricas. Em julho de 2009 na Libia, a representação brasileira foi a primeira a discursar como orador convidado em uma cúpula africana, na abertura da XIII Cúpula de Chefes de Estado e de Governo da União Africana (UA). Nesse encontro foram assinados três acordos complementares à Cooperação Técnica entre o Brasil e a União Africana, para a realização de acordos nas áreas de desenvolvimento sustentável da cadeia do algodão, de desenvolvimento social, agricultura e pesca. Percebe-se que a presença presidencial brasileira vem costurando o fortalecimento dos laços econômicos como também reforçando o legado da cultura africana construída no Brasil.

Esse conjunto de acontecimentos reúnem interesses econômicos com estratégias geopolíticas no campo da educação, gerando acordos econômicos e firmando a colaboração do Brasil com países africanos na área científica. Em 2004, em coordenação com o Ministério das Relações Exteriores, o Ministério da Ciência e Tecnologia fez o lançamento do "Programa de Cooperação Temática em Matéria de Ciência e Tecnologia" (PROÁFRICA) para financiamento de pesquisas conjuntas com pesquisadores africanos, a parceria com o Conselho Nacional de Desenvolvimento Científico e Tecnológico (CNPq) e a Coordenação de Aperfeiçoamento de Pessoal de Nível Superior (CAPES), para o financiamento do Programa de Estudantes-Convênio de Pós-Graduação, fornecendo bolsas de estudo de pós-graduação (mestrado e doutorado) para estudantes africanos.

Sabiamente o governo brasileiro além de expandir suas representações políticas, chega até alguns países do continente africano no campo do saber. Um saber, que parte do campo acadêmico e que pode vir a refletir nas escolas africanas com seus professores e alunos. Voltando a nossa indagação, o que seria melhor do que a CAPES, CNPq, UNILAB e a Fiocruz para arregimentar novos parceiros?

Em uma antiga relação de ensino-aprendizagem com África, seria de grande valia, como já salientaram Freire e Guimarães, (2003, p, 24) é preciso "pensar e refletir em sala de aula o tema do racismo, e das diferentes formas de opressão, violência e exclusão a que são submetidos os africanos e os afro-descendentes no Brasil". Como o processo de colonização dos povos africanos nos dias de hoje. Na mesma linha de raciocínio temos que exercitar em saber quais se as metas de pesquisa das universidades brasileiras estão relacionadas em aprender com a população e seu território e o local. O tema do reconhecimento e a proteção das comunidades locais vem sendo discutidos a décadas.

Essa proposta tomou força e consistência em 1998 com a aprovação pela Organização da Unidade Africana em Ougadougou, na Burkina Faso. Essa proposta é para implementar a Convenção sobre Diversidade Biológica (CDB) e o Acordo sobre Aspectos dos Direitos de Propriedade In- 
telectual Relacionados ao Comércio (Trips) da Organização Mundial do Comércio (OMC), especialmente em relação à proteção de variedades de plantas. A pesquisadora queniana Kameri-Mbote escreve que a lei-modelo africana objetiva a proteção dos conhecimentos tradicionais, aos recursos genéticos da fauna e flora. Segundo a autora (2003, p. 09) "a participação, de forma igualitária, na divisão dos benefícios derivados da utilização dos recursos genéticos de plantas e animais; a participação na tomada de decisões, inclusive no nível nacional" como nos demais assuntos relacionados à conservação e ao sustentável.

Entretanto, não podemos ser ingênuos, as ações governamentais brasileiras possuem metas a serem cumpridas, seja no campo da agricultura, importação, exportação de alimentos e a atração de população que buscam trabalhar nos países envolvidos. Uma ação política que coincide com demais interesses. Percebe-se que os pactos geopolíticos passam pela esfera cultural e econômica de negociação para implementação de novos contratos e parcerias

\section{REPENSANDO O DISCURSO GEOGRÁFI- CO}

Ao nos remetermos as novas relações do Brasil com a África, temos que abordar tais questões anteriores com seriedade na busca de encontrarmos alternativas para que o ensino do continente africano não fique estanque no tempo e no espaço. Esperamos que os conteúdos a serem trabalhados frutos dessa aproximação Brasil-África tenham significados, coerências e consistências na aprendizagem dos alunos por parte dos professores.

Acreditamos que a contribuição da Geografia escolar é abordar os fatos do mundo atual além das aparências, buscando as essências em ler o mundo, as paisagens e toda complexidade que marca esse conjunto de integração. As relações entre o Brasil e o continente africano estão cada vez mais estreitas por diversos interesses no contexto atual. No livro Por uma outra globalização, Milton Santos (2001) traz esse fato em três dimensões metafóricas "o mundo como fábula, como perversidade e como possibilidade". Para nós aqui interessa pensar nessa última como desafio, buscando ir além da racionalidade, tentando alcançar respostas de reação às duas anteriores.

Deixando de lado a fábula e perversidade, outro exemplo da adjacência brasileira aconteceu em 25 de maio de 2013, quando o Brasil esteve em Addis Abeba, na Etiópia, onde participou das comemorações do aniversário de 50 anos da União Africana que reúne 54 países. Temos aqui um recorte que merece destaque em sala de aula, que é a União Africana. Organização que vem sendo fortalecida desde o século XIX, com o tema dos 50 anos do Pan-africanismo e o Renascimento africano. Movimento pan-africanista, que foi decisório na organização política do continente africano ${ }^{2}$ . Sendo esse uma orientação política e sociocultural que visava eliminar a exploração e colonização europeia, levando a união do continente africano, em que os estados conseguissem suas independências.

A delegação brasileira foi a única convidada a levar um Chefe de Estado nas celebrações dentre os países da América Latina. A presidente teve reuniões de caráter político, econômico e cultural com o primeiro-ministro da Etiópia, Hailemariam Desalegn, que tem interesse nos programas de desenvolvimento agrícola, de transferência de renda e de educação implementados no Brasil. Essa parceria veio envolver novas e diferentes integrações.

Em pronunciamento, o Brasil declarou que está em processo o perdão com a dívida de 12 países africanos: Costa do Marfim, Gabão, Guiné, Guiné Bissau, Mauritânia, República Democrática do Congo, Congo, São Tomé e Príncipe, Senegal, Sudão, Tanzânia e Zâmbia. O indulto brasileiro pode ser abordado em sala de aula como uma futura projeção das empresas brasileiras nas novas relações comerciais, realçando as antigas heranças políticas com países de décadas passadas. Essa negociação visa a nosso ver uma geopolítica que se comunica com os empresários africanos e brasileiros. Esse acordo faz parte da velha roupagem chamada, agora de a velha-nova Divisão Internacional do Trabalho (DIT). Para que a DIT se concretize em forma de mercadoria, essa depende da produção e do trabalho. O Brasil insere os chamados países periféricos africanos no processo produtivo do capital, em que esses oferecem matérias primas, energia e mão-de-obra barata em troca da uma parcela do lucro. Tais elementos veem fazendo parte da política internacional brasileira que ganham destaque no eixo Sul-Sul de cooperação, mas que como já salientamos, possui como finalidade uma cadeira no Conselho de Segurança da ONU.

Entre os dias 30 de junho e $1^{\circ}$ de julho de 2013, ocorreu na sede da União Africana encontro de alto nível, "Novos enfoques unificados para acabar a fome na África", organizado pela UA e FAO, onde o Brasil defendeu que a presença brasileira no continente africano seja diferente daquela adotada pelos chineses, europeus e americanos colonialistas. Podemos nos perguntar, até que ponto o capital brasileiro será diferente dos demais, por exemplo do europeu? E por que seria? A lógica de reprodução do capital está na sua reprodução versus exploração. Santos (2001, p, 151) nos alerta para "o desafio do sul" em estabelecer novas parcerias, mas que essas também não criem dependências na cooperação.

A reunião teve como objetivo debater a segurança alimentar, a erradicação da fome e a desnutrição na África. Para os chefes africanos foi necessário saber as estratégias utilizadas pelo governo do Brasil no combate à fome e acesso à educação. Diretrizes que podem nortear projetos similares 
em andamento nos países africanos. Com esse fim foram discutidos um conjunto de medidas, princípios e políticas com foco em estratégias que subsidiassem os planos nacionais e regionais de investimento do programa Introduzindo o Programa Compreensivo para o Desenvolvimento da Agricultura em África' - CAADP. Sua meta é propor estratégias específicas sobre o tema de segurança alimentar e do desenvolvimento social, visando apoiar os países africanos a implementar novas experiências bem sucedidas no Brasil.

Podemos dizer que as ações do governo brasileiro buscam alcançar os três caminhos de ação para com os países desse continente, economia, política e cultura. A Geografia do imperialismo não acabou, não foi somente parte das Sociedades Geográficas ao iniciar a descolonização, a desmontagem dos antigos impérios nos anos sessenta. $\mathrm{O}$ colonialismo de hoje não está baseado na força, em doutrinas nobres como civilização e desenvolvimento, mas na ajuda humanitária. O governo brasileiro propõe ir além do que as nações europeias buscavam impor aos "novos" territórios conquistados. Além da língua, os chamados "bons" costumes e valores, o Brasil oferece agora apoio na integração no campo do saber, saúde, cultura e um melhor posicionamento no mundo do globalitarismo. As ações brasilianas podem ser analisadas no campo do racismo disfarçado. $\mathrm{O}$ autoritarismo que possui a roupagem da educação com a distribuição de bolsas de estudos, cuidados com a saúde, a implantação de fazendas modelos e a negociação das dívidas em troca de subsídios econômicos para as empresas brasileiras.

Falamos de um novo tipo de império colonial, onde a supremacia econômica se enlaça com os traços culturais para favorecer e legitimar a presença do mais forte. Sabemos que essas discussões podem ser construídas de diferentes maneiras em sala de aula, seja com figuras, mapas, texto e demais representações. Um exemplo simples é retomada do passado para explicar o presente. A presença territorial do Brasil no continente africano que vem a cada dia tomando maiores força e intensidade. Pressupõe-se ao professor um conhecimento mínimo da sua ciência para essa discussão em sala de aula, se não cairemos na ingenuidade humana.

Como já registrado anteriormente, não somos contrários as novas dimensões geográficas estabelecidos, mas acreditamos ser importante pensarmos de como elas vem sendo construídas por parte do governo e do empresariado. Em aproximar a teoria da lei com a prática estabelecida pelo governo brasileiro. Como também nos questionamos, até que ponto o poder público africano possui interesses e contradições diante das missões empresariais brasileiras como "Petrobras, Eletrobras, e as grandes construtoras, como Norberto Odebrecht, Andrade Gutierrez e Mendes Junior"?

\section{O CURRÍCULO COMO PROPOSTA POLÍ- TICA CULTURAL}

Nesse tópico temos como meta trazer o professor e o aluno para a reflexão de um currículo cultural escolar baseado no cotidiano. Partidário do ensino do continente africano nas escolas e universidade e principalmente na Geografia, onde pouco se faz a esse respeito, nosso exercício nesse texto é o da "reflexão crítica" como diz Chervel (1990, p. 177).

$\mathrm{Na}$ ousadia de inserir as discussões anteriores no material didático e na sala de aula, algumas delas podem vir a passar pelo exercício debate da cultura escolar, por releituras, diálogos e discussões de como tratar o tema. Se a meta for superar o que já foi feito, será necessário estarmos atentos para o desenvolvimento dessas propostas de trabalho no ensino. Da mesma forma não podemos deixar que esses conteúdos se transformem em meros instrumentos simbólicos escolares. É preciso que criemos sentido significativo para essa aliança estabelecida, incorporando as próprias ações da sociedade como questionar, replicar e contextualizar demais acontecimentos levantados pela escola e a sociedade como um todo.

Em pesquisa anterior Ferracini (2012, pp.203-209), demonstra que o ensino de África em alguns dos debates geográficos "estiveram ausentes na política educacional brasileira, negligenciando o continente africano nas páginas dos livros escolares e na grade curricular"'. Entretanto, existem pontos que precisam ser ressaltados nessa abordagem escolar, como, por exemplo, o posicionamento econômico do Brasil enquanto hegemonia econômica, política e cultural perante a África.

Acreditamos ser importante pensarmos com cuidado essa nova escala territorial. Será que as empresas e o governo brasileiro cometeram as mesmas armadilhas que as europeias? Lembramos do médico Fanon psiquiatra combatente do exército francês (1961, p. 164) quando escreveu: Se a construção de uma ponte não vai enriquecer a consciência
daqueles que nela trabalham, então não se construa a ponte,
continuem os cidadãos a atravessar o rio a nado ou numa bal-
sa. A ponte não deve cair do céu num pára-quedas, não deve
ser imposta por um deus ex machina ao panorama social, mas
deve, pelo contrário, sair dos músculos e do cérebro dos cida-
dãos. .

Concordando com antilhano, caso contrário, será necessário retomarmos a discussão do imperialismo, com a velha roupa colorida, disfarçado. Nós, professores, precisamos falar em sala de aula, cobrar nos cursos de formação de professores e nas grades curriculares de licenciaturas em Geografia o debate a respeito desse posicionamento do Brasil perante os países africanos. Nota-se que o "Projeto Político 
Pedagógico" implantado pelo governo brasileiro, ultrapassou os limites territoriais políticos, econômicos e culturais, sendo um marco para as futuras gerações no campo do ensino e aprendizagem no Brasil como na África. Em nossa análise ele busca reparar os erros cometidos pelos cinco séculos de atrocidades com os africanos como registrado pelo MEC/ SEPPIR 2003. Entretanto, não se pode deixar cair na ingenuidade da irmandade. Sabemos que no campo escolar o Projeto Político Pedagógico brasileiro deve estar baseado como diz Veiga (1998, p. 02) em "ir além de um simples agrupamento de planos de ensino e de atividades diversas". No mesmo parágrafo a autora afirma que "Ele é construído e vivenciado em todos os momentos, por todos os envolvidos com o processo educativo da escola". Acreditamos que é preciso unir conteúdos e saberes africanos e brasileiros para mudarmos e construirmos outro foco que não seja o etnocêntrico.

A Geografia e a Educação de uma forma ou de outra, com o tempo buscarão o entendimento dessa realidade pelos diferentes métodos. No campo acadêmico ou escolar os pressupostos metodológicos também serão distintos. No caso da disciplina escolar pode ser que essa conversa seja incorporada nos currículos escolares de maneira descritiva, analítica, fragmentada, estática ou crítica demonstrando ou não os diferentes horizontes das novas escalas de ações entre o Brasil e África. Esperamos que essa discussão, de certa forma, possa levar uma abertura maior de novas perspectivas, de leituras críticas, de uma facilidade de assimilação do conhecimento evidenciando o papel político, econômico e cultural do Brasil perante os países africanos e na América Latina.

Concomitante, temos um continente que vem passando por transformações e superações do processo secular de roedura e das ditaduras internacionais e nacionais. A Geografia e a Educação conhecem os elementos dessa realidade. Se um dos objetivos da Educação é educar para libertar, a postura filosófica e pedagógica dos professores não pode ser de poupar esforços para debater a presença do Brasil em território africano. Com a obrigatoriedade do ensino de África no currículo escolar temos que reeducar nossos olhos para o papel da Geografia enquanto ciência do território usado, de uma paisagem modificada, do lugar do Brasil e da África no mundo e de uma nova regionalização mundial e escolar que vem sendo construída.

\section{6. À GUISA DE CONCLUSÃO}

Esse debate está só começando. Pautado no ensino crítico acreditamos que seja possível desenvolver o esse tema em sala de aula. $\mathrm{O}$ entendimento dessa realidade não deve ficar limitado somente às ações descritivas e fragmentadas nas ações do governo brasileiro. As diretrizes educacionais devem passar pelas relações espaço-tempo a qual as ações governamentais podem levar. Para conseguirmos essa discussão no campo da aprendizagem é preciso entendê-las em sua totalidade, no processo contraditório e na relação dialética como foram postas. Nesse sentido, o currículo escolar comprometido com a realidade deve estar baseado no método dialético. Por parte do professor é preciso uma postura teórica e metodológica para não cair na armadilha do conteudismo das propostas didáticas e diretrizes curriculares. Pelo aluno é preciso curiosidade no conhecimento histórico dos países africanos, leitura e discussão. Por parte da escola, uma proposta política de como abordar esse tema em conjunto com outras disciplinas, como literatura, filosofia, artes, educação e sociologia. Concomitante cabe ao conjunto envolvido na escola e na sala de aula estabelecer conversas com outras áreas. Destarte, insistimos que o professor analise e reflita a respeito do processo de ensino e aprendizagem desse conteúdo.

A Lei é uma obrigatoriedade para as escolas, entretanto Giroux (1997, p.24) nos ensina que a escola é não somente o local de transmissão de conhecimento, mas de "construção política e cultural". Assim ela pode incentivar no desenvolver o senso crítico, a criatividade como a debater os problemas do mundo, mas precisamos contextualizar com os alunos o porquê de um conjunto de propostas e ações veem sendo implementadas pelo governo brasileiro no continente africano. Sabendo disso, retomamos as indagações do início desse texto, até que ponto esse movimento institucional é benéfica politicamente para os países, leia-se estados africanos envolvidos? Estaria a economia africana entrando na dependência do Brasil? Duas suposições que merecem atenção no desenvolvimento das atividades em sala de aula pelo professor com os seus alunos.

Para o desenvolvimento desse exercício diário em sala de aula são várias as publicações a respeito do continente africano, envolvendo diferentes debates teóricos e metodológicos. No conjunto destas escolhas não podemos ser acríticos, é preciso recordar a história da nossa ciência, para entendermos o presente a qual está inserida. Ou seja, ao recorrermos alguns temas do passado o debate se ampliará, podendo facilitar a compreensão da realidade atual. Enfim, espera-se que a cultura escolar brasileira ao tratar da África e das relações com o Brasil seja diferente daquela do olhar colonizador. Uma ação política e educativa que vem ganhando força pela cobrança dos diferentes movimentos sociais, das organizações civis e que pode ser refletida nas ações educativas da cultura escolar. O desafio é então, que se construam e solidifique os novos caminhos metodológicos, nos permitindo entender os sujeitos envolvidos, a transformar os dados em informações que nos ajudem a explicar essa aproximação 
para a escola básica, para os cursos de Geografia da graduação e na formação de professores. Que se aproxime a teoria da prática estabelecida e não caíamos na antiga armadilha colonial racista dos séculos passados.

\section{REFERÊNCIAS}

ASANTE S. K. B. e CHANAIWA, D. O Pan-africanismo e a Integração Regional. In: MAZRUI, A.A.; WONDJI, C. (Orgs) História geral da África, VIII: África desde 1935. Brasília: UNESCO, 2010. 1272 p.

BOAHEN, A. A. (Org.) História geral da África, VII: África sob dominação colonial, 1880-1935. 2.ed. rev. Brasília: UNESCO, 2010. 1040 p.

CHERVEL, A. História das disciplinas escolares: reflexões sobre um campo de pesquisa. Teoria \& Educação. Porto Alegre (RS), v. 2, 1990. p. 177-229.

COOPERAÇÃO BRASILEIRA PARA O DESENVOLVIMENTO INTERNACIONAL: 2011 - 2013 / Instituto de Pesquisa Econômica Aplicada; Agência Brasileira de Cooperação. - Brasília: IPEA: ABC, 2016. 184 p

FANON, F. Os Condenados da Terra. Ed. Civilização Brasileira, 1961, p. 275.

FERRACINI, R. A África e suas representações no(s) livro(s) escolares de Geografia no Brasil: de 1890 a 2003. Tese de Doutorado, FFLCH, USP, 2012. 229 p.

FREIRE, P.; GUIMARÃES S. A África ensinando a gente. São Paulo: Paz e Terra, 2003. 228 p.

GIROUX, H. Teoria Crítica e Resistência em Educação. Petrópolis: Vozes, 1983.

LÊNIN, V. I. El Imperialismo, Fase Superior del Capitalismo. In: Obras Escogidas. Moscou Editorial Progresso, 1976, t. 1, 130 p.

KAMERI-MBOTE, P. Community, farmers' and breeders' rights. Africa: towards a legal framework for sui generis legislation. Genebra: International Environmental Law Research Centre, 2003.

MINISTÉRIO DA EDUCAÇÃO; SECRETARIA ESPECIAL DE POLÍTICAS DE PROMOÇÃO DA IGUALDADE RACIAL. Diretrizes Curriculares Nacionais para a Educação das Relações Étnico-Raciais e para o Ensino de História e Cultura Afro-Brasileira e Africana. Brasilia: MEC, 2004.
SANTOS, M. Por uma outra Globalização: do pensamento único à consciência universal. Rio de Janeiro: Record, 2001.

VEIGA, I. P. Projeto político-pedagógico da escola: uma construção coletiva. In: VEIGA, I. P. (org.) Projeto político-pedagógico da escola: uma construção possível. Campinas: Papirus, 1998. p.11-35.

\section{Notas de Fim:}

1- De acordo com o IPEA (2016, p.55) os projetos cooperativos em agricultura desenvolvimento tecnológico da agropecuária, agrofloresta e meio ambiente são em Angola, Argélia, Cabo Verde, Camarões, Guiné-Bissau, Moçambique, São Tomé e Príncipe, Senegal, Tanzânia e Tunísia.

2- Segundo o ganês Asante e o zimbabuano Chanaiwa (2011, p. 899). O pan-africanismo defendia a "África para os africanos" com direito a terra, recursos, identidade e a união dos africanos".

\section{Correspondência do autor:}

Rosemberg Lopes Ferracini e-mail: rosemberggeo@yahoo.com.br

Artigo recebido em: 08/06/2017

Revisado pelo autor em: 04/12/2017

Aceito para publicação em: 11/02/2018 